\title{
Phytochemical Analysis and Antioxidant Activity of Cotinus coggygria Scop. from Armenian Flora
}

\author{
N.K. Shaboyan', A.V. Moghrovyan'2, K.H. Dumanyan², N.H. Ghukasyan², A.A. Altunyan², N.I. Arshakyan², A.M.

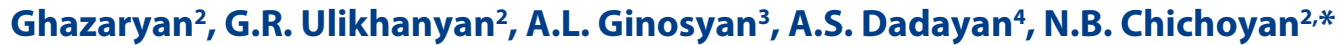

\section{N.K. Shaboyan' ${ }^{1}$, A.V.}

Moghrovyan², K.H. Dumanyan², N.H. Ghukasyan², A.A. Altunyan², N.I. Arshakyan², A.M. Ghazaryan², G.R. Ulikhanyan², A.L. Ginosyan", A.S. Dadayan ${ }^{4}$, N.B. Chichoyan ${ }^{2, *}$

'Institute of Pharmacy YSU, 0025, 1 Alek Manukyan st, Yerevan, RA, ARMENIA.

${ }^{2}$ Yerevan State Medical University after M.Heratsi, Department of Pharmacognosy, 0025, 2 Koryun st., Yerevan, RA, ARMENIA. ${ }^{3}$ Analytical laboratory after Academician Emil Gabrielyan", branch of "Scientific center of drug and medical technology expertise" CJSC, 0051, Komitas Ave., 49/4, Yerevan, RA, ARMENIA.

${ }^{4}$ Scientific and Production Center

"Armbiotechnology» of National Academy of Sciences RA, 0056, 14 Gyurjyan Str., Yerevan, RA, ARMENIA.

\section{Correspondence}

\section{N.B. Chichoyan}

Yerevan State Medical University after M.Heratsi, Department of Pharmacognosy, 0025, 2 Koryun st., Yerevan, RA ARMENIA

E-mail: n.chichoyan@mail.ru

History

- Submission Date: 29-01-2021

- Review completed: 09-03-2021;

- Accepted Date: 02-04-2021.

DOI : 10.5530/pj.2021.13.120

Article Available online

http://www.phcogj.com/v13/i4

Copyright

(C) 2021 Phcogj.Com. This is an openaccess article distributed under the terms of the Creative Commons Attribution 4.0 International license.

\section{ABSTRACT}

Armenian flora is stood out by the variety of its medicinal and edible plants. Here small plants as well as trees and shrubs are met. Cotinus coggygria of Armenian flora is used in folk medicine. The aim of this investigation was to determine the chemical composition of Armenian flora's smoke trees leaves' essential oil and antiradical activity of ethanol extract of leaves and branches of smoke tree. Methods: The aerial parts were extracted by hydrodistillation method, and the composition was analyzed by gas chromatograph interfaced to a mass spectrometer. Antiradical activity of essential oil from leaves and branches was determined by using appropriate methods. Results: The total amount of flavonoids has been determined in the leaves of the smoke tree by miricetin. This analysis revealed that the flavonoid amount in ethanol extract of C. coggygria, growing in Armenia, was 0,94\%. In volatile oil of Smoke tree leaves 22 compounds were determined. The results demonstrated that in the essential oil of leaves of Cotinus from Armenian flora predominated Germacrene D, Linalool, formate, $\alpha$-Terpineol sesquiterpenes and diterpene alcohol Thunbergol. Ethanol extracts of leaves and branches of Smoke tree showed antioxidant activity. Conclusion: From the results, it is evident that $C$. coggygria from Armenia flora contains various bioactive compounds and the extracts of leaves pronounced higher antioxidant activity and recommended as a plant of phytopharmaceutical importance.

Key words: Cotinus coggygria Scop., Essential oil, Ethanol extract, Antiradical activity, DPPH.

\section{INTRODUCTION}

Nowadays, from the standpoint of obtaining biologically active raw materials, wild plants are noticeable because of the interest in their massgrowing habitats and significant raw material reserves. Most notable are pharmaceutical raw materials containing polyphenolic compounds that have a broad spectrum of pharmacological activity (used as a coagulant, anti-inflammatory, antibacterial, etc.). From this point of view, the plants belonging to the family Anacardiaceae are quite unique. Some plants in this family are widely cultivated as edible plants, some are poisonous, others serve as medicines and a source of wood.

Cotinus coggygria (Cotinus coggygria Scop., Synonymous with Rhus cotinus L.) belongs to the family Anacardiaceae, growing up to $5-12 \mathrm{~m}$ high, spherical or canopy foliage, $18 \mathrm{~cm}$ thick, leafy shrub covered with brownish bark. This plant is usually either considered as large shrubs or small trees. It has glaucous, simple, ovate or obovate leaves, $3-8$ $\mathrm{cm}$ long. The flowers are pentamerous, pale yellow or yellow-green, hermaphrodite or some of them abortive, with long peduncles, in terminal loose inflorescences. This plant grows in the Caucasus, Crimea, northern Ukraine, Central Asia, Georgia, usually in dry places, often on mineral and sandy slopes, at $1500 \mathrm{~m}$ above sea level.

According V. Koleva and E. Simeonov(2014) Cotinus coggygria is wide spread in Southern Eu- rope, the Balkans, and Southwestern and Central Asia. Extracts from the leaves, twigs, wood, and inflorescences of the plant are used in the ethnomedicine of Eastern and Southeastern Europe and China as antidiarrhoetic, anti-inflammatory and antiparadentosis. ${ }^{1}$ Cotinus coggygria, also known as the "smoke tree", is one of the two species constituting a small genus of the family Anacardiaceae, viz., $C$. coggygria Scop. (syn.: Rhus cotinus L.) and Cotinus obovatus Raf., the American smoke tree. It has a wide distribution from southern Europe, the Mediterranean, Moldova and the Caucasus to central China and the Himalayas. ${ }^{2}$

Due to the results of a mass spectrometric study of essential oil obtained from the leaves of Cotinus coggygria Scop growing in Turkey, 42 active components were found, representing $99.6 \%$ of the total components detected. The major constituents were identified as limonene $(48.5 \%),(Z \quad)$ $(+)$ - $\beta$-ocimene $(27.9 \%)$ and $(E)$ - $\beta$-ocimene $(9.7 \%){ }^{3}$

Similar research was done on raw materials cultivated from Smoke trees growing in Serbia and Greece.The quantitative contents were different, and in all cases the predominant ingredient was limonene. In this study, the Smoke tree leaves were standardised based on limonene, while in scientific sources it is based on myrcene.

The leaves of Smoke trees growing in Georgia were studied. Antioxidant activity of phenolic fraction obtained from the leaves extract was confirmed. ${ }^{4} \mathrm{~A}$

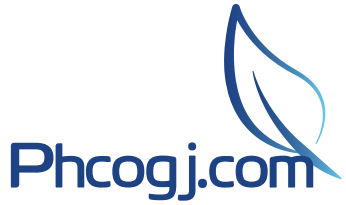

Cite this article: Shaboyan NK, Moghrovyan AV, Dumanyan $\mathrm{KH}$, Ghukasyan NH, Altunyan AA, Arshakyan NI, et al. Phytochemical Analysis and Antioxidant Activity of Cotinus coggygria Scop. from Armenian Flora. Pharmacog J. 2021;13(4): 933-941. 
total of 30 compounds were identified in essential oil of Rhus cotinus the dominant components were monoterpenes $(65,9 \%)$, which were bettapinene, camphene, limonene, alpha-pinene and p-cymene followed by sesquiterpene hydrocarbons $(20,6 \%)$.The oil exhibited antioxidant activity by inhibiting betta- carotene bleaching $(56.4 \pm 1.88 \%)$, and by scavenging $\mathrm{DPPH}$ free radical $\left(\mathrm{IC}_{50}=720 \pm 0.10 \mu \mathrm{g} \mathrm{Ml}{ }^{-1}\right) .{ }^{5} \mathrm{In}$ another study the antimicrobial activity of the young shoots of the smoke tree was investigated. The acetone extract and the derived ethyl acetate fraction effectively inhibited the growth of Gram-positive and Gramnegative bacteria (MIC $25-200 \mu \mathrm{g} / \mathrm{ml}$ ), while the chloroform fraction showed pronounced activity against the yeast Candida albicans (MIC $3.12 \mu \mathrm{g} / \mathrm{ml}$ ). The ethyl acetate fraction exhibited a significant ferricreducing ability $(10.7 \mathrm{mmol} \mathrm{Fe}(2+) / \mathrm{g}$ extract), a very high $\mathrm{DPPH}$ radical scavenging activity $\left(\mathrm{SC}^{50}=1.7 \mu \mathrm{g} / \mathrm{ml}\right)$ and inhibition of lipid peroxidation $\left(\mathrm{IC}^{50}=41.8 \mu \mathrm{g} / \mathrm{ml}\right)$. High amounts of total phenolics $(929.8 \mathrm{mg} / \mathrm{g})$, tannins $(833.8 \mathrm{mg} / \mathrm{g})$ and flavonoids $(35.5 \mathrm{mg} / \mathrm{g})$ were determined in the ethyl acetate fraction, which also exerted significant anti-inflammatory $(76.7 \%)$ and cytotoxic effects $\left(\mathrm{IC}^{50}=15.6 \mu \mathrm{g} / \mathrm{ml}\right)^{.6}$ In the study by the author Saini Shagun et al. (2016) 19 compounds were identified in the essential oil of Cotinus. The compounds characterizing major peaks were a-Phellandrene(7,83\%), a-Mircene (5,36\%), (+)-2-Bornanone(14,52\%), Caryophyllene (7,65\%), (+)-epiBycyclosesquiphellandrene (5,59\%), c-Elemene (9,56\%), Globulol (7,95\%). The composition of monoterpene hydrocarbons was observed dominant over sesquiterpene hydrocarbons. ${ }^{7}$ The author Sanja Matic' et al. reported that the Anacardiaceae Lindl. family comprises of many species which are used in nutrition and in traditional folk medicine for the treatment of several human diseases. Cotinus coggygria Scop. commonly known as "smoke tree", is a commercial ornamental plant with high medicinal usages, belongs to the family Anacardiaceae.

The plant has been extensively investigated in a broad range of studies to provide scientific evidence for folklore claims or to find new therapeutic uses. Numerous activities namely antioxidative, antibacterial, antifungal, antiviral, anticancer, antigenotoxic, hepatoprotective and anti-inflammatory have been demonstrated for all parts of these plants by in vivo and in vitro studies. Essential oils and extracts showed various pharmacological and biological properties which make them an effective remedy for various kinds of illnesses. Considering data from the literature, it could be demonstrated that $C$. coggygria possesses diverse bioactive properties and immense utilization in medicine, health care, cosmetics and as health supplements. ${ }^{8}$

Cotinus coggygria is an important herbal medicine in Armenia. From this point of view, it is quite interesting that Cotinus coggygria typical to the Caucasus region especially growing in the flora of Armenia, the pharmacognostic study of which can be promising in terms of locally sourced raw materials and production. Smoke trees are found in Armenia in the low and middle mountainous areas of Tavush and Syunik regions. It grows on rocky slopes, in bushes and forest edges.

So, the aim of this research was to study the phytochemical and comparative antioxidant activity of the leaves and branches of smoke tree growing in Armenia.

\section{MATERIALS AND METHODS}

\section{Plant materials and essential oil extraction}

Cotinus coggygria leaves and shrubs collected in Yerevan, $40^{\circ} 10^{\prime} 51^{\prime \prime} \mathrm{N}$, Longitude: $44^{\circ} 30^{\prime} 48^{\prime \prime}$ E Elevation above sea level: $994 \mathrm{~m}=3261 \mathrm{fduring}$ the blossoming period (july 2019). The primary processing and drying of a raw material was carried out by WHO instructions (GACP, WHO 2011), The identification of plant was carried out at the Department of Pharmacognosy, Yerevan State Medical University (Armenia). Plant samples were deposited and are available at the Herbarium of the Institute if Botany, National Academy of Sciences of Armenia,Yeravan
(Armenia). A voucher specimen number is ERE 193405. EO was extracted from the aerial parts of leaves plants by hydro-distillation method (with Clevenger -type apparatus) that lasted approximately 4 h. The distilled essential oils were dehydrated with anhydrous sodium sulfate and was stored at $+4 \pm 1^{\circ} \mathrm{C}$ in the dark for further use. ${ }^{9}$

\section{Gas chromatography/mass spectrometry (GC-MS) analysis}

The EO composition was analyzed at the "Analytical laboratory after academician Emil Gabrielyan", branch of "scientific center of drug and medical technology expertise" CJSC (Armenia). GC analysis was carried out using a gas chromatograph (BRUKER 450-GC, USA. An OPTIMA-FFAP capillary column $(0.25 \mathrm{mkm}, 60 \mathrm{~m} \mathrm{x} 0.25 \mathrm{~mm}$ (ID, MACHEREYNAGEL, Germany) was used for the separation of volatile oil compounds. Helium gas carrier flow-rate $1.0 \mathrm{ml} / \mathrm{min}$, volume of injected sample $2 \mathrm{mkl}$, the oven temperature $220^{\circ} \mathrm{C}$, temperature gradient $50^{\circ} \mathrm{C}(2 \mathrm{~min})$, split-separation -5 . Compounds were identified using the NIST Mass spectral. The identification of peaks was tentatively carried out based on library search using NIST $-2013 .^{10}$

\section{Ethanol extracts preparation and determination of total flavanoid content by myricetin}

Flavanoids have low or moderate solubility in water, the extraction was made using dried plant material to eschew the dilution of the solvent. Aerial parts of leaves plants were at $55{ }^{\circ} \mathrm{C}$ for $24 \mathrm{~h}$. 1 g powdered dried aerial parts of leaves was homogenized in 10 to $15 \mathrm{ml} 40 \%$ ethanol and left over overnight at $10^{\circ} \mathrm{C}$. The extract was centrifuged for $5 \mathrm{~min}$ at $5000 \mathrm{grm}$, and the supernatant was isolated. The precipitate was extracted by 4 -folds, and the combined supernatant was dried by evaporation at room temperature. The evaporated mass was solved in ethanol, and the extracts in different dilutions were used. The absorbance of the extract was measured $(415 \mathrm{~nm})$ with the spectrophotometer Genesis $10 \mathrm{~S} \mathrm{UV}$ Vis (Thermo Scientific, USA), and total flavonoid content of EE was expressed in terms of myrcetin $\left(\mathrm{E}^{1 \%} /{ }_{1 \mathrm{sm}=} 380 /\right.$ myrcetin+ $\left.\mathrm{AICI}_{3} /\right)$.

Total flavonoid content $(\%)=\mathrm{D} \times 100 \times 2$

$380 \mathrm{x} \mathrm{m} \times 2$

Where $\mathbf{m}$ - mass of the row material

D- optic density

The total flavonoid content in the ethanol extract of leaves of cotinus was determined using aluminium chloride colorimetric assay. ${ }^{11}$

\section{$D P P H$ (free radical-scavenging) assay}

Scavenging free radical potentials were determined in ethanol solution of DPPH. ${ }^{22}$

In the research, the methanol, a stable radical of DPPH ((2,2-diphenyl1-picrylhydrazyl, $\mathrm{C}_{18} \mathrm{H}_{12} \mathrm{~N}_{5} \mathrm{O}_{6}, \mathrm{M}=$ (394.33) (Sigma Aldrich $\mathrm{GmbH}$ )) and the dry methanol extracts of the leaves and shrubs of $C$. coggyria were used.

The antioxidant activity determination was carried out using the spectrophotometric method, in which the natural antioxidant interacts with the stable chromogen radical DPPH. The antioxidant activity was determined after the interaction of the methanol solution of DPPH with the test solution and was calculated using a calibration graph of the DPPH (the dependence of the optical density from the DPPH concentration). The absorbance of the samples was determined at the wavelength $515 \mathrm{~nm}$.

The optical density definition of the testing solutions was performed by the device Helios Comp Thermoelectron (England). The measurements were carried out in five replicates. The optical density of the DPPH was recorded after 1, 5 and 20 minutes. 
The scavenging effect in percentage was defined according to this formula:

Antioxidant Activity $(\%)=\left(\left(\mathrm{C}_{\mathrm{c}}-\mathrm{C}_{\mathrm{ext}}\right) / \mathrm{Cc}\right) \mathrm{x} 100 \%$,

$\mathrm{C}_{\mathrm{c}}$-concentration control absorbance,

$\mathrm{C}_{\text {ext }}$-concentration corresponds to the absorbance in the presence of extracts

Antioxidant activity was calculated as the effective concentration at which the DPPH radicals were inhibited by $50 \%\left(\mathrm{IC}_{50}\right){ }^{13-15}$

\section{Statistical analysis}

Statistical analysis was made by SPSS ${ }^{\bullet}$ for Windows (Version 16.0, Chicago, IL, USA). The results were presented as a mean \pm standard error of mean; $\mathrm{p}<0.05$ was regarded as statistically significant.

\section{RESULTS AND DISCUSSION}

\section{Essential oil composition}

The GC/MS analysis of oil has revealed that the essential oil of Cotinus coggygria growing in Armenian flora consists of many complex compounds. According to GC-Ms dates, in the volatile oil of Smoke tree leaves 22 compounds were identified. Regarding the composition of the studied EOs, significant differences in relation to the major components as well as the content of the different terpene classes was observed. Sesquiterpenes and diterpenes were most present classes in the oil of $C$. coggygria. The compounds characterizing major peaks were Germacrene D, Linalool, formate, $\dot{\alpha}$-Terpineol and Thunbergol $(10.65 \%, 10.04 \%, 8.78 \%$ and $6.87 \%$ resp.). The latter accompanies the volatile oil, which testified about olea-resina mixture. In oil of C. coggygria was revealed another sesquiterpenes, among which Cycloheptane, 4-methylene-1-methyl-2-(2-methyl-1-propen-1-yl)-1vinyl-(3.81\%), á-Humulene (2.68\%), Caryophyllene (2.65\%), followed by à-Muurolene (2.06\%) et al. (Table 1, Figure 1 ).

The total flavonoid content was expressed using the specific density for myrcetin, and the result was expressed as myrcetin specific density $\mathrm{E}_{\mathrm{Ier}}^{1 \%}=380$. Our studies have confirmed that the flavonoid amount in ethanol extract of C. coggygria, growing in Armenia, was 0,94\%.

\section{Free Radical Scavenging Activity (\% DPPH inhibition)}

The results of the study showed that all the samples of the raw material (smoke tree leaves and twigs) are manifested a positive antioxidant activity, determined by the rate of the DPPH inhibition.

Figure 2 shows the relationship between the optical density (D) and concentration $(\mathrm{C})$ of the experimented extracts for corresponding concentrations $2 \mathrm{mg}, 4 \mathrm{mg}$ and $8 \mathrm{mg}$; the results of which are given in Tables 2 and 3.

\section{Table 1: Phytocomponents identified in the essential oil of leaves of Smoke trees (Cotinus coggygria Scop.), growing in Armenian flora by GC-MS.}

\begin{tabular}{|c|c|c|c|c|}
\hline Compound name & Rt & Formula & $\mathrm{Mr}$ & Area $\%$ \\
\hline $\begin{array}{c}\text { 1. 1,6-Octadien-3-ol, 3,7-dimetl } \\
\text { Synonym: } \\
\text { Linalool, formate }\end{array}$ & 2.16333 & $\mathrm{C}_{11} \mathrm{H}_{18} \mathrm{O}_{2}$ & 182 & 10.04 \\
\hline $\begin{array}{c}\text { 2. 3-Cyclohexene-1-methanol, } \dot{\alpha}, \dot{\alpha} \\
\text { Synonym: } \\
\dot{\alpha} \text {-Terpineol }\end{array}$ & 2.45333 & $\mathrm{C}_{10} \mathrm{H}_{18} \mathrm{O}$ & 154 & 8.78 \\
\hline $\begin{array}{r}\text { 3. Bicyclo[3.1.1]hept-3-en- } \\
\text { 4,6,6-trimethyl- } \\
\text { Synonym: } \\
\text { Berbenone } \\
\text { Verbenone }\end{array}$ & 2.57 & $\mathrm{C}_{10} \mathrm{H}_{14} \mathrm{O}$ & 150 & 0.14 \\
\hline $\begin{array}{c}\text { 4.n-Valeric acid cis-3-hexen } \\
\text { Synonym: } \\
\text { cis-3-Hexenyl valerat }\end{array}$ & 2.68667 & $\mathrm{C}_{11} \mathrm{H}_{20} \mathrm{O}_{2}$ & 184 & 1.08 \\
\hline $\begin{array}{c}\text { 5.1,5-Dimethyl-1-vinyl-4-hexen } \\
\text { Synonym: } \\
\text { Linalyl butyrate }\end{array}$ & 2.957 & $\mathrm{C}_{14} \mathrm{H}_{24} \mathrm{O}_{2}$ & 224 & 1.71 \\
\hline $\begin{array}{c}\text { 6.Bicyclo[2.2.1]heptan-2-ol, 1,7,7-tri } \\
\text { endo- } \\
\text { Synonym: } \\
\text { Bornyl acetate }\end{array}$ & 3.507 & $\mathrm{C}_{12} \mathrm{H}_{20} \mathrm{O}_{2}$ & 196 & 4.44 \\
\hline $\begin{array}{c}\text { 7. 2-Oxopentanoic acid, } 2 \text {-acetyl } \\
\text { Synonyms: } \\
\text { no synonyms. }\end{array}$ & 3.69 & $\mathrm{C}_{13} \mathrm{H}_{14} \mathrm{O}_{4}$ & 234 & 0.31 \\
\hline $\begin{array}{c}\text { 8. (E)-2-Hexenyl tiglat } \\
\text { Synonyms: } \\
\text { no synonyms. }\end{array}$ & 4.41 & $\mathrm{C}_{11} \mathrm{H}_{18} \mathrm{O}_{2}$ & 182 & 0.54 \\
\hline $\begin{array}{r}\text { 9. 3-Cyclohexene-1-methanol, d́, } \dot{\alpha}, 4-\mathrm{t} \\
\text { Synonyms: } \\
\text { á-Terpineol acetate }\end{array}$ & 4.57 & $\mathrm{C}_{12} \mathrm{H}_{20} \mathrm{O}_{2}$ & 196 & 4.3 \\
\hline $\begin{array}{l}\text { 10. á-Cubebene } \\
\text { Synonyms: } \\
\text {.(-)-à-Cubebene }\end{array}$ & 5.01 & $\mathrm{C}_{15} \mathrm{H}_{24}$ & 204 & 0.96 \\
\hline $\begin{array}{l}\text { 11. Bicyclo[3.1.1] heptane-2-methano } \\
\text { [1S-(1à,2à,5à)]- } \\
\text { Synonyms: } \\
\text { cis-Myrtanol }\end{array}$ & 5.16 & $\mathrm{C}_{10} \mathrm{H}_{18} \mathrm{O}$ & 154 & 1.75 \\
\hline
\end{tabular}




\begin{tabular}{|c|c|c|c|c|}
\hline $\begin{array}{c}\text { 12. Caryophyllene } \\
\text { Synonyms: } \\
\text { á-Caryophyllen, trans-Caryophyllene }\end{array}$ & 5.837 & $\mathrm{C}_{15} \mathrm{H}_{24}$ & 204 & 2.63 \\
\hline $\begin{array}{l}\text { 13. } \beta \text {-Cubebene } \\
\beta \text {-Cuvebene }\end{array}$ & 6.04 & $\mathrm{C}_{15} \mathrm{H}_{24}$ & 204 & 1.17 \\
\hline $\begin{array}{c}\text { 14. } \dot{\alpha}-\text { Humulene } \\
\text { Synonyms: } \\
1,4,8 \text {-Cycloundecatriene, 2,6,6,9-tetramethyl-, (E,E,E)- }\end{array}$ & 6.55 & $\mathrm{C}_{15} \mathrm{H}_{24}$ & 204 & 2.68 \\
\hline $\begin{array}{l}\text { 15.Epizonarene } \\
\text { Synonyms: } \\
\text { no synonyms }\end{array}$ & 6.887 & $\mathrm{C}_{15} \mathrm{H}_{24}$ & 204 & 0.63 \\
\hline $\begin{array}{l}\text { 16. 1,6-Cyclodecadiene, 1-methyl-5-methylene-8-(1- } \\
\text { methylethyl)-, [s-(E,E)]- } \\
\text { Synonyms: } \\
\text { 1.Germacrene D }\end{array}$ & 7.193 & $\mathrm{C}_{15} \mathrm{H}_{24}$ & 204 & 10.65 \\
\hline $\begin{array}{l}\text { 17. (+)-Epi-bicyclosesquiphellandrene } \\
\text { Synonyms: } \\
\text { 1.1-Isopropyl-4-methyl-7-methylene-1,2,3,4,4a,5,6,7- } \\
\text { octahydronaphthalene }\end{array}$ & 7.33 & $\mathrm{C}_{15} \mathrm{H}_{24}$ & 204 & 0.78 \\
\hline $\begin{array}{l}\text { 18. Naphthalene, 1,2,4a,5,6,8a-hexahydro-4,7- } \\
\text { dimethyl-1-(1-methylethyl)-, (1à,4aà,8aà)- } \\
\text { Synonyms: } \\
\text { à-Muurolene }\end{array}$ & 7.5 & $\mathrm{C}_{15} \mathrm{H}_{24}$ & 204 & 2.06 \\
\hline $\begin{array}{l}\text { 19.Naphthalene, 1,2,3,4,4a,5,6,8a-octahydro-7-methyl- } \\
\text { 4-methylene-1-(1-methylethyl)-, (1à,4aá,8aà)- } \\
\text { Synonyms: } \\
\text { ç-Cadinene }\end{array}$ & 7.777 & $\mathrm{C}_{15} \mathrm{H}_{24}$ & 204 & 1.26 \\
\hline $\begin{array}{l}\text { 20. à-Cadinol } \\
\text { No sinonims }\end{array}$ & 10.667 & $\mathrm{C}_{15} \mathrm{H}_{26} \mathrm{O}$ & 222 & 0.27 \\
\hline $\begin{array}{l}\text { 21. Cycloheptane, 4-methylene-1-methyl-2-(2-methyl- } \\
\text { 1-propen-1-yl)-1-vinyl- } \\
\text { no synonyms. }\end{array}$ & 17.18 & $\mathrm{C}_{15} \mathrm{H}_{24}$ & 204 & 3.81 \\
\hline $\begin{array}{l}\text { 22. Thunbergol } \\
\text { No sinonims }\end{array}$ & 21.687 & $\mathrm{C}_{20} \mathrm{H}_{34} \mathrm{O}$ & 230 & 6.87 \\
\hline
\end{tabular}

Table 2: Correlation of the DPPH optical density and concentration.

\begin{tabular}{|c|c|}
\hline Optical density (D) & Concentration (c) \\
\hline \multicolumn{2}{|c|}{$c=20,06^{*} D+0,996$} \\
\hline 0,947 & 20 \\
\hline 0,05 & 2 \\
\hline
\end{tabular}

Table 3: The relationship between the optical density (D) and concentration (C) $\left[\left(x_{10} 0^{-5}\right) \mathrm{g} / \mathrm{l}\right]$ of the inhibition DPPH ( $\mathrm{n}=5, \bar{x}-$ mean, $E_{s-}$ standard error of the mean).

\begin{tabular}{|c|c|c|c|c|}
\hline \multirow{2}{*}{$\begin{array}{l}\text { Analytical samples of the } \\
\text { raw materials. }\end{array}$} & \multirow[t]{2}{*}{ Extract (mg) } & \multicolumn{3}{|c|}{$\begin{array}{l}\text { The time of the inhibition DPPH } \\
\qquad(\min ) \bar{x} \pm E_{s}\end{array}$} \\
\hline & & 1 & 5 & 20 \\
\hline \multirow{2}{*}{ Branches of C.coggygria } & ${ }^{*} \mathrm{D}-4$ & $0.443 \pm 0.008$ & $0.236 \pm 0.002$ & $0.236 \pm 0.007$ \\
\hline & D-8 & $0.422 \pm 0.008$ & $0.139 \pm 0.003$ & $0.139 \pm 0.004$ \\
\hline \multirow{2}{*}{ Branchesof C.coggygria } & ${ }^{\star} \mathrm{C}-4$ & $9.886 \pm 0.164$ & $5.74 \pm 0.04$ & $5.74 \pm 0.15$ \\
\hline & C-8 & $9.461 \pm 0.157$ & $3.786 \pm 0.068$ & $3.778 \pm 0.089$ \\
\hline \multirow{2}{*}{ branches of C.coggygria } & ${ }^{* *} \mathrm{D}-2$ & $0.245 \pm 0.002$ & $0.092 \pm 0.002$ & $0.092 \pm 0.002$ \\
\hline & D-8 & $0.118 \pm 0.002$ & $0.08 \pm 0.002$ & $0.08 \pm 0.002$ \\
\hline \multirow{2}{*}{ branches of C.coggygria } & ${ }^{* *} \mathrm{C}-2$ & $5.905 \pm 0.033$ & $2.835 \pm 0.044$ & $2.847 \pm 0.044$ \\
\hline & C-8 & $3.357 \pm 0.038$ & $2.598 \pm 0.035$ & $2.594 \pm 0.039$ \\
\hline
\end{tabular}

${ }^{* *} \mathrm{D}-2,{ }^{*} \mathrm{D}-4, \mathrm{D}-8$ - the values of the optical densities of the extracts with concentrations of $2 \mathrm{mg}, 4 \mathrm{mg}$ and 8 mg, respectively

${ }^{*} \mathrm{C}-2,{ }^{*} \mathrm{C}-4, \mathrm{C}-8$-the values of the concentrations of experimented herbal extracts $2 \mathrm{mg}, 4 \mathrm{mg}$ and $8 \mathrm{mg}$, respectively 

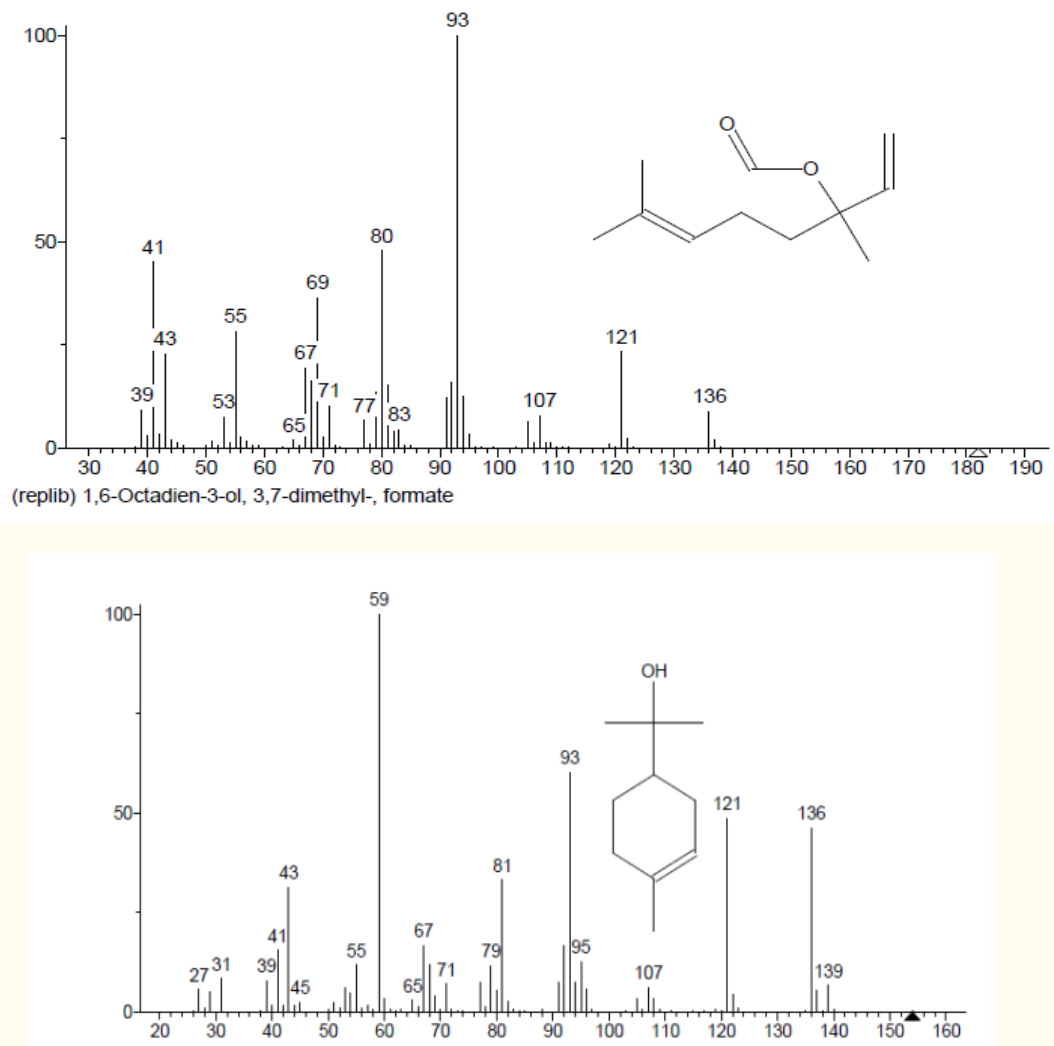

(replib) 3-Cyclohexene-1-methanol, alpha.,,alpha-4-trimethyl-

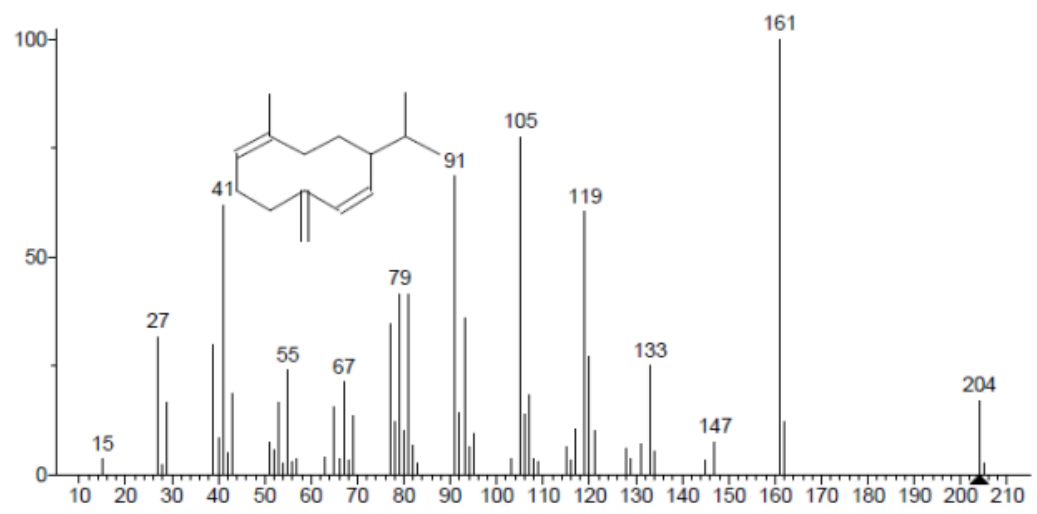
(mainlib) 1,6-Cyclodecadiene, 1-methyl-5-methylene-8-(1-methylethyl)-, [s-(E,E)]-

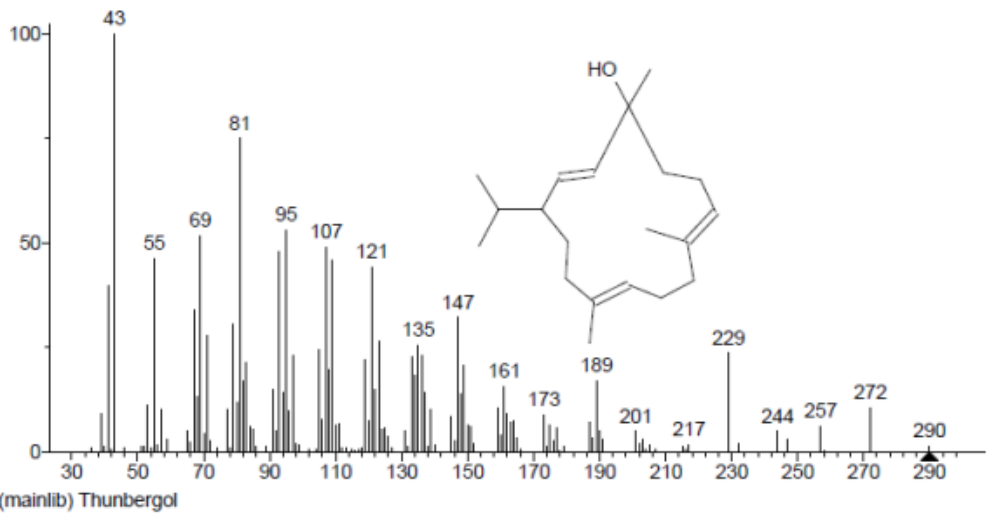

Figure 1: Mass spectrum and structure of phytocomponents identified by GC-MS in the essential oil of leaves Cotinus coggygria. 


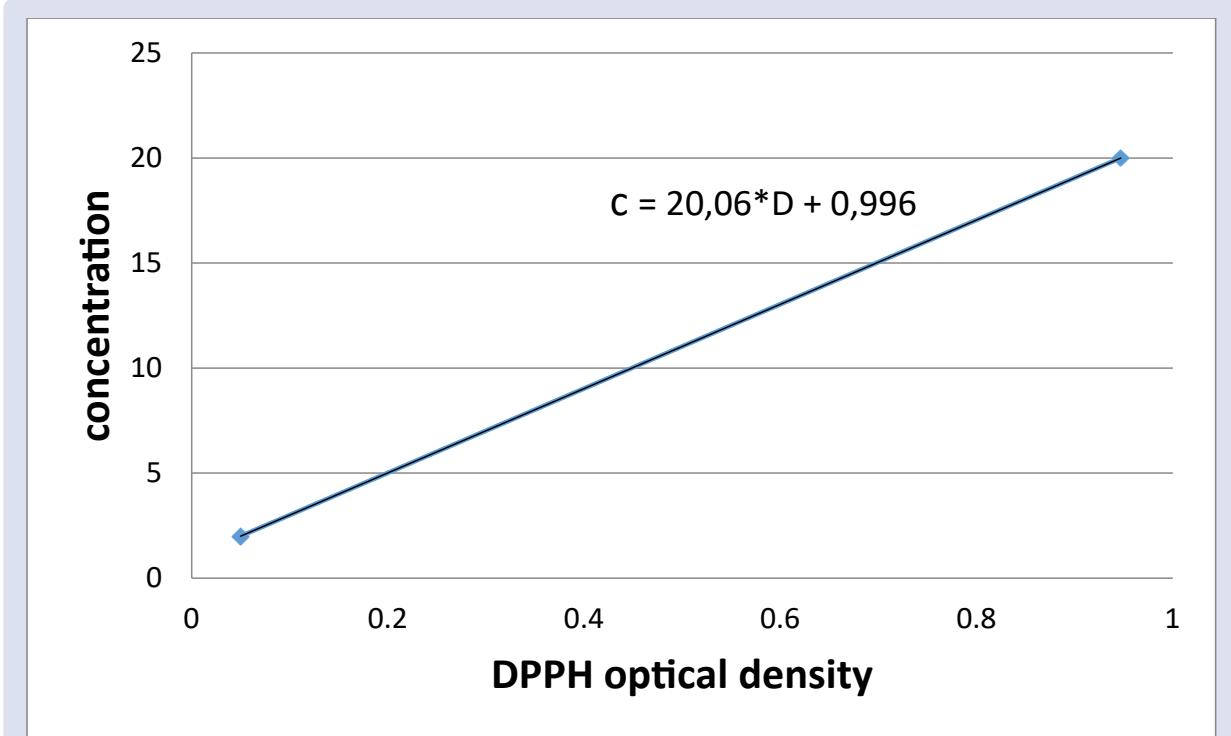

Figure 2: Correlation graph of the DPPH optical density and concentration.

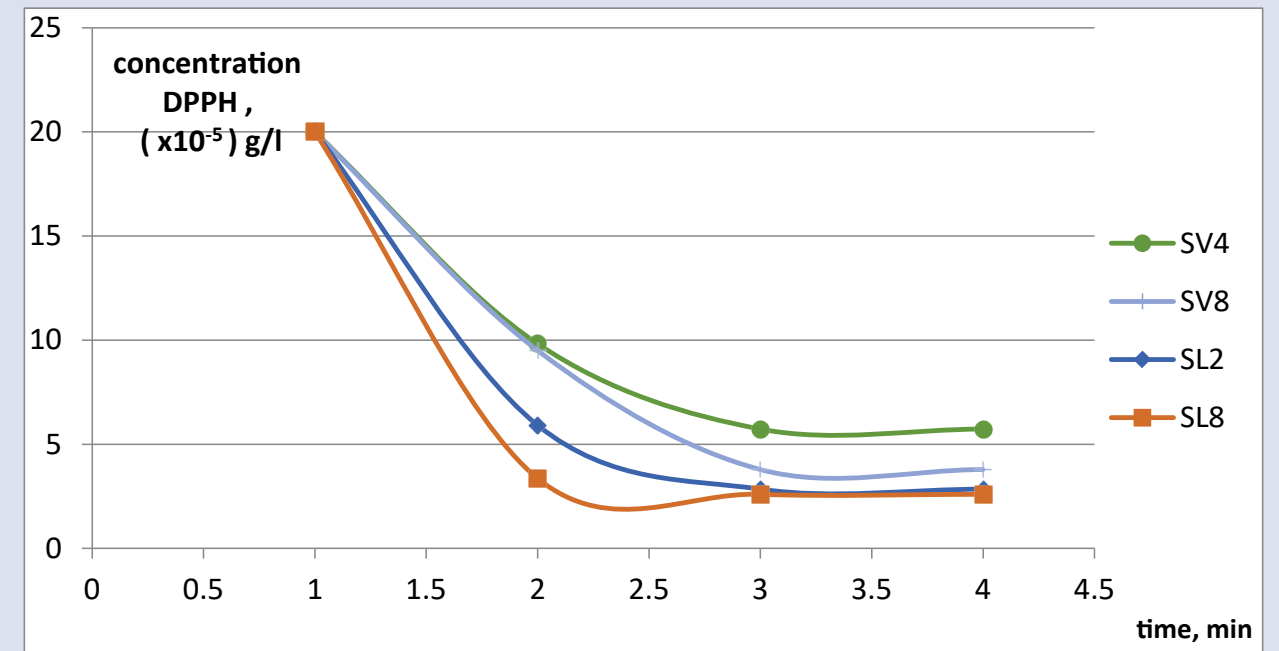

Figure 3: The relationship between the optical density (D) and concentration (C) of the experimented extracts for corresponding concentrations $2 \mathrm{mg}, 4 \mathrm{mg}$ and $8 \mathrm{mg}$. SV4 extract from shrubs - the concentration $4 \mathrm{mg}$; SV8 extract from shrubs- the concentration $8 \mathrm{mg}$; SL2 extract from leaves - the concentration 2mg; SL8 extract from leaves- the concentration $8 \mathrm{mg}$.

Table 4: The antioxidant activity of the dry $50 \%$ methanol extracts of leaves and branches of C. coggygria ( $n=5, \bar{x}-$ mean, $E_{s}-$ standard error of the mean).

\begin{tabular}{|c|c|c|c|c|c|}
\hline \multirow{3}{*}{$\begin{array}{l}\text { Analytical samples of } \\
\text { the raw materials. }\end{array}$} & \multirow{3}{*}{ Extract (mg) } & \multirow{2}{*}{\multicolumn{3}{|c|}{$\begin{array}{l}\text { The time of the inhibition DPPH, min and antioxidant activity } \\
\qquad \begin{array}{l}\text { (\%) } \bar{x} \pm E_{s}\end{array}\end{array}$}} & \multirow{3}{*}{$I C_{50}\left(\times 10^{-5}\right) \mathrm{g} / \mathrm{I}$} \\
\hline & & & & & \\
\hline & & 1 & 5 & 20 & \\
\hline \multirow{2}{*}{ branches of C.coggygria } & 4 & $50.57 \pm 0.82$ & $71.30 \pm 0.23$ & $71.30 \pm 0.75$ & $13.95 \pm 0.32$ \\
\hline & 8 & $52.70 \pm 0.79$ & $81.07 \pm 0.34$ & $81.11 \pm 0.45$ & $13.85 \pm 0.27$ \\
\hline \multirow{2}{*}{ leaves of C.coggygria } & 2 & $70.47 \pm 0.16$ & $85.83 \pm 0.18$ & $85.77 \pm 0.22$ & $2.64 \pm 0.49$ \\
\hline & 8 & $83.22 \pm 0.19$ & $87.01 \pm 0.17$ & $87.03 \pm 0.19$ & $2.37 \pm 0.11$ \\
\hline
\end{tabular}


The relationship between the optical density (D) and concentration (C) $\left[\left(x 10^{-5}\right) \mathrm{g} / \mathrm{l}\right]$ is shown in the Table 3 .

The results presented in the table (Table 4) show that smoke tree leaves extract exhibits the highest antioxidant activity: at a concentration of 8 $\mathrm{mg}$ of DPPH, the same antioxidant activity $(87.03 \pm 0.19)$ was observed within 5 le 20 minutes. Unreliable difference observed between registered indicators $(\mathrm{p} \geq 0.05)$.

The extract of the smoke tree branches showed the lowest activity, the antioxidant activity index of which was $50.57 \pm 0.82$ in the first 1 minute at a concentration of $4 \mathrm{mg}$ of DPPH.

It is noteworthy that at all concentrations of the extract of the leaves and branches, the same antioxidant activity is observed during the 5th l. 20th minutes. That is, an unreliable difference is noticed between the measures $(p \geq 0,05)$. It should be noted that branch extracts have less antioxidant activity than leaf extracts. The concentrations of antioxidants was also calculated during the study (IC50) that inhibited $\mathrm{DPPH}$ radicals by $50 \%$. As it is seen from the table $\mathrm{IC}_{50}$ values were in the range from $64 \pm 0.49$ to $13.95 \pm 0.32(\mathrm{x} \mathrm{10-5)} \mathrm{g} / \mathrm{l}$.

Thus, the study results showed that the extracts of the branches and leaves of smoke trees growing in Armenia have a pronounced antioxidant activity, with the indicators differ from each other in the rate of reaction. The Leaves extract has the highest activity. The highest IC50 was recorded in the branch extracts, which showed low antioxidant activity.

The highest values $\left(\mathrm{IC}_{50} 13.95 \pm 0.32\right.$ and $\left.13.85 \pm 0.27\left(\mathrm{x} 10^{-5}\right) \mathrm{g} / \mathrm{l}\right)$ of extracts were received from the branches $C$. coggygria for the concentrations $4 \mathrm{mg}$ and $8 \mathrm{mg}$ respectively had the smallest of antioxidant activity.

\section{CONCLUSIONS}

Analyses of the volatile constituents from the leaves of Cotinus coggygria collected from Yerevan indicate Germacrene D, Linalool formate, $\dot{\alpha}-$ Terpineol sesquiterpenes and diterpene alcohol Thunbergol which are the predominant components of Cotinus coggygria. This work provides the first report of the analysis of essential oils of Cotinus coggygria from Armenia. At the same time, the results of the research showed that the leaves and shrubs might be further applied as a new natural antioxidant ingredient in the medicine.

\section{ACKNOWLEDGMENTS}

The authors gratefully acknowledge the Botanical Garden, Armenian National Academy of Sciences for technical support of this study. Scientific-Technological Center of Organic and Pharmaceutical Chemistry National Academy of Sciences RA, the Scientific and Production Center "Armbiotechnology» of National Academy of Sciences RA, the analytical laboratory «FDA Lab». The authors also want to thank the editors and reviewers for their kind and precious comments and suggestions that made this manuscript into a better version.

\section{CONFLICTS OF INTEREST}

The authors declare no conflicts of interest.

\section{REFERENCES}

1. V. Koleva and E. Simeonov. Solid Liquid Extraction of Phenolic and Flavonoid Compounds from Cotinus coggygria and Concentration by Nanofiltration Chem. Biochem. Eng. Q., 28 (4) 545-551 (2014).

2. Miroslav M Novaković., Ivan Vuckovic; Pedja Janackovic; Marina Soković. Chemical composition, antibacterial and antifungal activity of the essential oils of Cotinus coggygria from Serbia. Journal of the Serbian Chemical Society 72(11). November 2007, DOI: 10.2298/JS C0711045N.

3. Demirci B., Demirci F., Baser K. H. C. "Composition of the essential oil of Cotinus coggygria Scop. from Turkey", Flavour and Fragrance Journal, vol. 18, issue 1,p. 43-44, 2003.

4. Alania M, Shalashvili K, Sagareishvili T, Kavtaradze N, Sutiashvili M Georgian Med News. Study of antioxidant activity of phenolic compounds from some species of georgian flora2013. Sep;(222):6972.

5. Subhash C. Joshi1 and C. S. Mathela. Essential oil composition of Rhus cotinus and its antioxidant activity. J. Nat. Prod. Plant Resour., 2014, 4 (3):39-43.

6. Phytother Res. 2013 Nov;27(11):1658-63. doi: 10.1002/ptr.4919. Epub 2012 Dec 27. Antimicrobial, antioxidant and anti-inflammatory activity of young shoots of the smoke tree, Cotinus coggygria Scop. Marčetić $M^{1}$, Božić D, Milenković M, Malešević N, Radulović S, Kovačević N.

7. Saini Shagun, Bhattacharya Sujata*, Sharma Manjul. Chemical Profiling, Antioxidant and Antibacterial Properties of Cotinus coggygria Essential Oil from Western Himalaya. International Journal of Pharmacognosy and Phytochemical Research 2016; 8(7); 11831186 ISSN: 0975-4873.

8. Sanja Matic', Snežana Stanic', Mirjana Mihailovic', Desanka Bogojevic, Cotinus coggygria Scop.: An overview of its chemical constituents, pharmacological andtoxicological potential. Saudi Journal of Biological Sciences.Volume 23, Issue 4, July 2016, Pages 452-461.

9. Quality control methods for herbal materials // World Health Organization.-Malta.-2011.-173p.

10. 10.NIST Standard Referance Database 1A. http://www.nist.gov/srd/ upload/NIST 1a11 Ver2-OMan.pdf/.

11. 11.Zou Y, Lu Y, Wei D. Antioxidant activity of a flavonoid -rich extract of Hypericum perforatum L. in vitro. J Agric Food Chem 2004; 52(16):5032-9.

12. 12. Moon JK, Shibamoto T. Antioxidant assays for plant and food components. J.Agric. Food. Chem 2009. 57(5): 1655-66. [http://dx. doi.org. /10.1021/jf803537k] [PMID:19182948.

13. 13. V.Bondet, W.Brand-Williams,C.Berset .Kinetics and Mechanisms of Antioxidant Activity using the DPPH.Free Radical Method. Food Science and Technology. Volume 30, Issue 6, September 1997, P.609615.

14. 14. AnanikyanV,Yeribekyan M, Mnatsakanyan V. Accelerated method for the detecting the antiradical activity of organic compounds. Globe of Sci. 2007;7: 31-33.

15. 15.Mnatsakanyan VA, Yeribekyan MI, Ananikyan VV. Comparative evaluation of the antiradical activity of some isoquinoline alkaloids. Globe of Sci. 2009; 8: 31-33. 


\section{GRAPHICAL ABSTRACT}

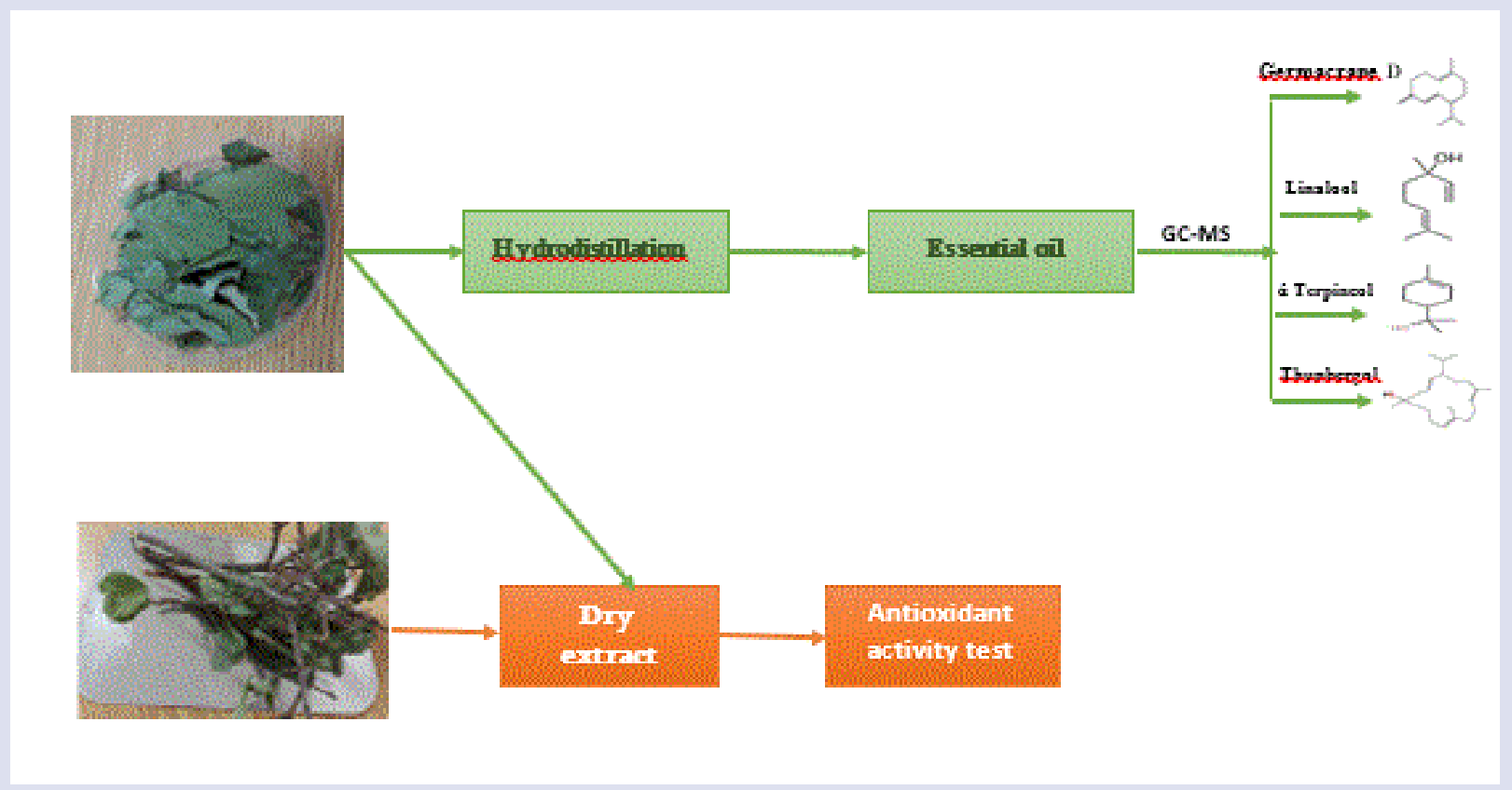

\section{ABOUT AUTHORS}

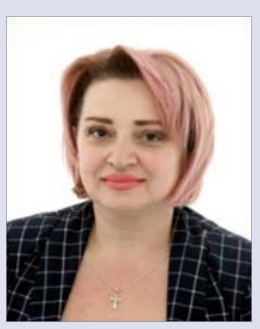

Naira B. Chichoyan, head of the Department of Pharmacognosy, Yerevan State Medical University, Doctor of Pharmaceutical Science, Associate Professor.

Supervisor of a research project "The pharmacognostic research of wild-growing and cultivating medicinal plant species of Republic of Armenia and Artsakh flora".

Author of more than 80 scientific works, 3 manuals and a monograph.

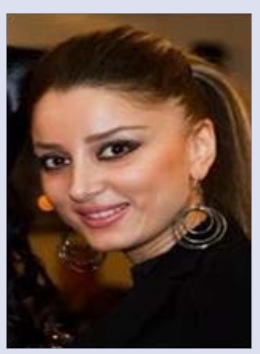

Naira K. Shaboyan, 2014-2019- attended courses at University of Basel, Faculty of Natural Sciences, Department of Pharmacology, Switzerland.

2020-up to this day works at Galenica Pharmaceutical Company (Galenica AG Pharmaceuticals Bern, Switzerland).

The research project is "The pharmacognostic research of Armenian flora".

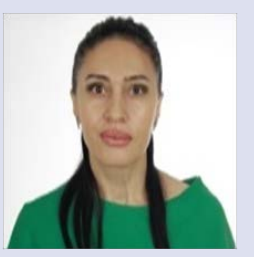

Armenuhi V. Moghrovyan, Senior lecturer at the Department of Pharmacognosy, YSMU, after Mkhitar Heatsi, PhD. The research project is "The pharmacognostic research of Armenian flora". Particularly the scope of scientific interest is "The pharmacognostic and biological activity analysis of Oregano ordinary (Herba Origani vulgaris) growing wildly in Armenian flora."

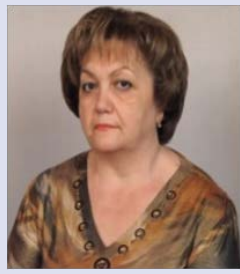

KARINE H. DUMANYAN, Associate Professor at the Department of Pharmacognosy, YSMU, after Mkhitar Heatsi , PhD. The research project is "The pharmacognostic research of Armenian flora". Within the framework of the research project she implements the identification of endemic plants. More than 30 years teaches Botany in Pharmacy Faculty. 

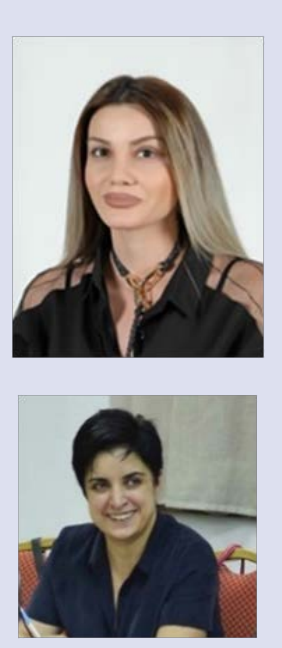

Nelli H. Ghukasyan, lecturer at the Pharmacognosy Department, YSMU, after Mkhitar Heatsi. The research project is "The pharmacognostic research of Armenian flora". Also, has an interest on the phytochemical analysis of bulbous-rooted chervil growing wildly in different regions of Armenia. More than 10 years of multilingual teaching.

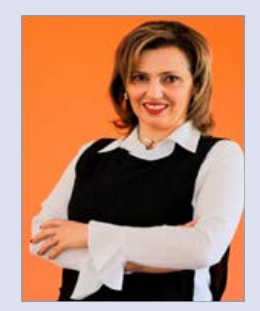

Astghik A. Altunyan, lecturer at the Department of Pharmacognosy, YSMU, after Mkhitar Heratsi The research project is "The pharmacognostic research of Armenian flora".

Efficient, hard-working, knowledgeable and technically skilled employee who works well both individually and in a team environment.

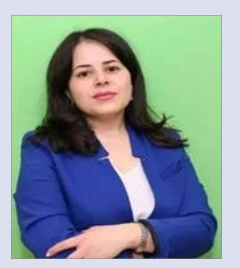

Naira I.Arshakyan, assistant at the Department of Pharmacognosy,YSMU, after Mkhitar Heratsi The research project is "The pharmacognostic research of Armenian flora". Author of some scientific articles.

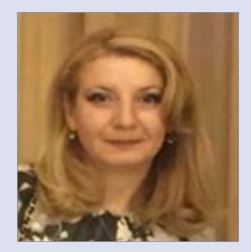

Arshaluys M.Ghazaryan, graduated from YSMU, after Mkhitar Heratsi with honours in 2016 and started working as an assistant at the Department of Pharmacognosy. She is a resident of the Department.

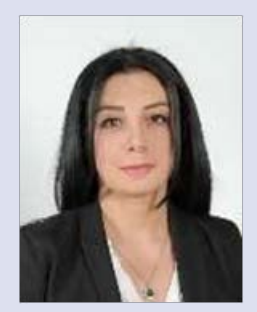

\section{Greta R.Ulikhanyan}

Lecturer at the Department of "Medical physics " of the

Yerevan State Medical University after. M. Heratsi

Scientific interests - application physico-chemical methods for standardization raw materials of plants using in the medico-pharmaceutical practice.

Aghavni V. Ginosyan, $\mathrm{PhD}$ in Chemical engineering eMBA in Healthcare Management, Director of Analytical Laboratory branch of «Scientific Center of Drug and Medical Technology Expertise after Academician E.Gabrielyan" JSC. Lecturer, tutor on Analytical Method Validation, Stability Testing and Quality Management Systems.Yerevan State University, Institute of Pharmacy, Department of Pharmacy.

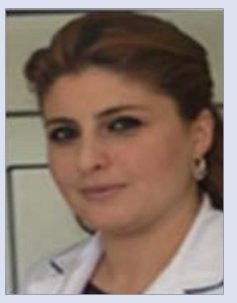

Ani S. Dadayan, Secretary of Scientist's Board of Institute of PharmacyYSU,Assistant of Department of Pharmtechnology and Pharmacy Economics \& Managment, PhD in Chemistry

Scope of scientific interests - Syntheses of new modified chiral auxiliaries and their amino and dehidroamino acid complexes and investigation in asymmetric biomimetic reactions for the syntheses of $\alpha$ - and $\beta$-substituted non-proteinogenic (R)- and (S)- $\alpha$ - mino acids. Prodaction of Galenic and Newgalenic preparations and herbal origin oils.

Cite this article: Shaboyan NK, Moghrovyan AV, Dumanyan KH, Ghukasyan NH, Altunyan AA, Arshakyan NI, et al. Phytochemical Analysis and Antioxidant Activity of Cotinus coggygria Scop. from Armenian Flora. Pharmacog J. 2021;13(4): 933-941. 